\title{
GESAMTKUNSTWERK Arte contemporáneo y cultura mediática en Boris Groys
}

\author{
GESAMTKUNSTWERK \\ Contemporary Art and Media Culture in Boris Groys
}

\author{
VICTOR LENARDUZZI \\ victorh!@fibertel.com.ar
}

Teorías y Prácticas de la Comunicación I, Facultad de Ciencias Sociales. Universidad de Buenos Aires / Arte y Cultura de Masas, Facultad de Ciencias de la Educación. Universidad Nacional de Entre Ríos. Argentina

Recibido 21/11/2018 | Aceptado 17/3/2019

\section{Resumen}

Este artículo se propone abordar las relaciones entre cultura mediática y arte contemporáneo en la obra teórica y crítica de Boris Groys poniendo especial énfasis en la idea wagneriana de obra de arte total retomada por el autor. Para ello, a partir de una breve descripción de obra de arte, se introduce una descripción de la categoría y el uso que le da Groys para analizar la cultura del stalinismo, las formas del arte contemporáneo y sus relaciones con la cultura mediática en la actualidad.

\section{Palabras clave}

Obra de arte total; arte contemporáneo; cultura mediática; estetización

\section{Abstract}

This article aims to address the relationship between media culture and contemporary art in the theoretical and critical work of Boris Groys, placing special emphasis on the Wagnerian idea of total work of art taken up by the author. For this, from a brief description of work of art, we present a description of the category and use given by Groys to analyze the culture of Stalinism, the forms of contemporary art and their relationship with media culture today.

\section{Keywords}

Total art; contemporary art; mediatic culture; aestheticization 
Dos perros doberman negros custodian el pabellón alemán. Los actores y las actrices - vestidos con ropa deportiva y de aspecto posgénero- circulan por todas partes, incluso debajo de donde está ubicado el público (que a su vez puede desplazarse) en un piso que es totalmente transparente y establece dos niveles. Los cuerpos se entrelazan, se mueven, quedan enredados en poses donde poder, deseo, sometimiento, temor, angustia y soledad, entre otras imágenes, aparecen de manera efímera como acciones en un clima de carácter opresivo. Escenas entre la sumisión y una lánguida seducción. Agua, toallas mojadas, fuegos encendidos, cucharitas metálicas, una guitarra. Los visitantes quedan en situaciones en las que deben ganarse un lugar para ver qué sucede, ya que las acciones transcurren no solo en la sala central sino en dos salas adyacentes que se pueden ver a través de unas ventanas que limitan el acceso visual. Los smartphones omnipresentes: todos quieren llevarse fotos y videos, aun la directora se comunica con sus actores a través de mensajes. La música y el sonido —en muchos momentos sonoridad antes que músicason potentes y para algunos difícil de soportar; se tapan los oídos, pero son graves que van al cuerpo, no a los tímpanos. Entre ambient y hard techno, bien podría asimilarse al tipo de sonido que uno podría experimentar en algún buen club nocturno berlinés. Sin dudas, la experiencia no sería tan intensa si no sonara así.

Estoy tratando de describir, seguro sin éxito, la obra Faust, de Anne Imhof, una suerte de performance e instalación (sin duda más de lo primero, algo de lo segundo) presentada en la 57a Bienal de Venecia, Viva Arte Viva, durante 2017 [Figura 1]. Tuve la oportunidad de verla dos veces, la segunda quizá para poder hacer algo con el impacto que produce. Pero al escribir sobre ella aparece la característica distancia entre acontecimiento y documento que atraviesa hoy los debates estéticos. Era recurrente en comentarios y críticas de la obra de Imhof señalar que retomaba dos grandes hitos de la cultura alemana: el Faust de Goethe, obra literaria fundacional, y la idea wagneriana de Gesamkunstwerk (obra de arte total). Resulta interesante agregar que Faust en alemán significa 'puño', lo que aportaría connotaciones afines con la escenificación opresiva en un pabellón de aspecto duro —en 1938 durante el nazismo - reformado por el arquitecto Ernst Haiger.

Obra de arte total. Esta idea, a través de la cual se podía caracterizar la propuesta de Imhof, es el título y el tema de este artículo. Lo que nos proponemos es trabajar en una caracterización del concepto en la reflexión crítica de Boris Groys, con el fin de trazar las líneas que el autor aporta a la comprensión de las relaciones entre comunicación y arte contemporáneo en el marco de la cultura actual. Para esto delimitamos zonas de interés: primero, reponemos el concepto de obra de arte total en Wagner y el uso de Groys para pensar la cultura estalinista; segundo, indagamos sobre la utilidad de esta categoría para analizar el arte contemporáneo y, finalmente, ponemos esto en contacto con las formas de la cultura mediática. 



\section{Arte total}

El concepto de Gesamtkunstwerk fue planteado por el compositor alemán Richard Wagner. Se trata de un Kompositum que reúne en un concepto nuevo una serie de ideas. Wagner nos resulta muy conocido por su trabajo musical, pero aquí se trata de retomar la idea que planteó en Das Kunstwerk der Zukunft [La obra de arte del futuro], un texto escrito en 1849 y publicado en 1850, mientras estaba exiliado en Zurich. Allí se ensayan una serie de críticas a la moda, el lujo y la superficialidad y, además, al egoísmo del artista, ya que es el pueblo, la comunidad, el eje de su apuesta en torno a lo que el arte debería ser. La idea se expandió e internacionalizó hace ya tiempo; sin embargo, no es tan común para los hispanohablantes y tampoco ha estado presente en la crítica de la comunicación y la cultura a pesar de su fertilidad. Boris Groys, cuyas reflexiones son parte central de nuestro interés, la recoge en diferentes ensayos e, incluso, la convirtió en título de uno de sus libros, referido al arte y la cultura stalinista.

Wagner articuló la idea para su propia forma de ver el drama musical y en el marco de una concepción que apuntaba hacia la convergencia de las artes y la superación de sus fronteras. A partir de las mediaciones de la vista, el oído y el lenguaje establecía que las tres «hermanas originarias» eran el arte de la danza, el arte del sonido y el arte de la poesía. Aunque cada uno estaba prisionero de sus límites: cuando se derriben las fronteras «no existirán más ni esa especie artística ni tampoco esos límites, sino solo el arte, el ilimitado y mancomunado arte mismo» (Wagner, [1850] 2011, p. 45). La relación entre arte y vida es tematizada en términos de una conexión con la vida de la cual el arte debe dejar de avergonzarse, porque es de la vida de donde puede extraer materia y forma. La fuerza vital para el arte es el pueblo, quienes tienen algo «en común» y todos aquellos que sienten «una urgencia comunitaria» (Wagner, [1850] 2011, pp. 23-24). Para Wagner el artista de su época era un egoísta distante y aislado del pueblo, que debía trascender esa circunstancia en el comunismo, que implicaba el autosacrificio del artista en función de un colectivo, el pueblo, que era el verdadero artista.

El lujo y la moda eran algo así como un infierno al que ponerle fin para llegar a «disfrutar en común, en común seremos humanos de verdad. En común anudaremos el lazo con la sagrada necesidad, y el beso fraterno que sellará esa unión será la obra de arte en común del futuro» (Wagner, [1850] 2011, p. 26). Lo que aparece tematizado al momento de formular la idea de obra de arte total es la consecución de una fusión entre los diferentes géneros, entre los artistas y entre artistas y público.

La gran obra de arte total, la que deberá abarcar todos los géneros del arte, a los que en cierta medida, en tanto medios, utilizará, aniquilará, en favor de alcanzar la meta común a todos ellos, esto es la representación incondicionada e inmediata de la completa naturaleza humana, esta gran obra de arte total no la reconoce como la posible acción de un individuo, sino pensable necesariamente como obra conjunta de los hombres del futuro (Wagner, [1850] 2011, p. 36). 
Sería una suerte de utopía comunitaria que apunta a superar las divisiones entre especialidades y roles artísticos para revertir lo que constituía una especie de cercenamiento de las capacidades humanas, que la obra del futuro debería trascender. Una apuesta de Boris Groys (2008a) fue poner en juego el concepto de Gesamtkunstwerk para comprender la deriva de la Rusia posrevolucionaria de la consolidación de Stalin. Así, afirma que el «proyecto de una nueva organización estética de la sociedad ha sido propuesto y hasta se ha probado más de una vez en Occidente, pero sólo en Rusia tuvo pleno éxito por primera vez» (Groys, 2008a, p. 29). De ahí que ninguna revolución occidental se haya comportado de manera tan cruenta con el pasado como lo hizo la revolución rusa, agrega. Y lleva las cosas todavía más allá: señala la perplejidad de las miradas marxistas racionales que veían como paradójico que la revolución sucediera en un país atrasado tanto técnica como culturalmente, para agregar:

\section{[...] Rusia estaba mucho más preparada que Occidente para la revolución, es decir, estaba dispuesta en mucho mayor medida a organizar toda su vida en formas nuevas nunca vistas, y a permitir, a ese fin, que se la sometiera a un experimento artístico organizado de una envergadura nunca vista (Groys, 2008a, p. 30).}

Al abordar la deriva de la vanguardia rusa se atreve a poner en duda la "opinión corriente de que el stalinismo significó el fin de la vanguardia, de que la vanguardia después de la mitad de los años treinta dejó de ser una fuerza histórica real» para sostener que sus "ambiciones y estrategias fueron apropiadas y utilizadas a su manera por la cultura staliniana» (Groys, 2008a, pp. 14-15). Esto le valió recriminaciones por referirse a esa continuidad sin enfatizar la diferencia entre una y otra.

En el «Prólogo a la primera edición rusa» del libro sobre Stalin, Groys se detiene sobre el sentido del título de su libro para especificar que en la actualidad se entiende

\footnotetext{
[...] al concepto de «Gesamtkunstwerk» corresponde, más que nada, el concepto de multimedialidad, que designa la utilización de diferentes medios en el marco de una misma obra de arte. Así, en la ópera, la música, el texto, la actuación y la escenografía se integran en una obra de arte única, total, que, como esperaba Wagner, puede resultar capaz de someter completamente la percepción y la imaginación del espectador, si influye simultáneamente en todos los sentidos de éste. También la realidad soviética de la época estaliniana puede ser descrita como una única escenificación multimedial: como una obra de arte total, capaz de absorber e incorporar completamente dentro de sí a su espectador (Groys, 2008a, pp. 12-13).
}

Más tarde, en su ensayo "Instalar el comunismo» (2016a), Groys retoma la cuestión de la producción de lo real como una obra de arte y sugiere que «se podría decir que la Unión Soviética como totalidad fue diseñada como una suerte de instalación artística, una obra de arte cuyos límites coincidieron con las fronteras del territorio soviético» (p. 103).

En síntesis, el concepto de Gesamtkunstwerk ha resultado productivo como estrategia interpretativa en diversos contextos y experiencias. Veamos entonces cómo opera esa idea en el marco del arte contemporáneo. 


\section{De lo moderno a lo contemporáneo}

Analicemos otra experiencia artística. Entre 2017 y 2018 se llevó a cabo en Buenos Aires en el Centro Cultural Kirchner la exposición Les Visitants [Figura 2], basada en el acervo de la Fundación Cartier. La gran muestra incluyó obras de unos veinitrés artistas de diferentes lugares del mundo y en diversos formatos. En la misma podían verse desde el video de Nan Goldin, Balada de la dependencia sexual (1979-1995) hasta Laberinto de espejosojos inertes (2003), de Tony Oursler, pasando por la serie de fotografías Desnudos (2017), de David Lynch. Inspirado en un dibujo del cineasta el espacio El living room de David revisitado estuvo a cargo del artista argentino Guillermo Kuitca y permitía algo así como introducirse en un cuadro (porque en realidad se recreaba en una instalación). Kuitca había sido invitado por la Fundación Cartier para oficiar como curador de la exhibición.

La aparición de Kuitca en el papel de curador, más allá su trayectoria como artista, resulta significativa para introducir rasgos que caracterizan a la producción artística en la actualidad: el ascenso de los curadores, la pregnancia de los proyectos de exhibición y tendencia a ver lo exhibido como obra total. En este marco, resulta significativo cómo los museos dejaron de ser espacios de elegidos para transformarse en medio de masas y dar lugar a cierta espectacularización dirigida - muchas veces - a convocatorias masivas. La relación entre museo y exhibición temporal implicó una redefinición de roles y profesiones, por lo que la figura del curador y la práctica curatorial han adquirido una relevancia notable en el arte contemporáneo. Respecto de esta cuestión ha señalado Andreas Huyssen (2001):

\footnotetext{
La aceleración que se está produciendo en la definición laboral del curator se refleja incluso en la gramática: ahora existe el verbo to curate, y precisamente no limitado a las funciones tradicionales del «conservador» de colecciones. Por el contrario, hoy día to curate significa movilizar las colecciones, ponerlas en movimiento dentro de los muros del museo al que pertenecen y por todo el planeta, así como en las cabezas de los espectadores (pp. 52-53).
}

Dicha transformación para Huyssen se inscribe en la pérdida de vigencia de la dialéctica museo/modernidad y en cierto borramiento de los límites entre museo y proyecto de exhibición que se verifica en el auge de las exposiciones temporales y una nueva vida online de las actividades museísticas. Con la postmodernidad ya vuelta demodé —cuando hasta no hace tanto parecía ser la definición de una nueva época- el problema de la contemporaneidad (y sus múltiples temporalidades) tomó la posta en la caracterización de la producción estética que la adjetivación moderno parecía no poder contener más. Si bien con polémicas y desacuerdos, la idea de un tránsito del arte moderno al contemporáneo se ha instalado de manera significativa (Giunta, 2014; Jimenez, 2010; Smith, 2012). Uno de sus síntomas es la cristalización institucional: no hay museos de arte posmoderno, sino museos de arte contemporáneo. 

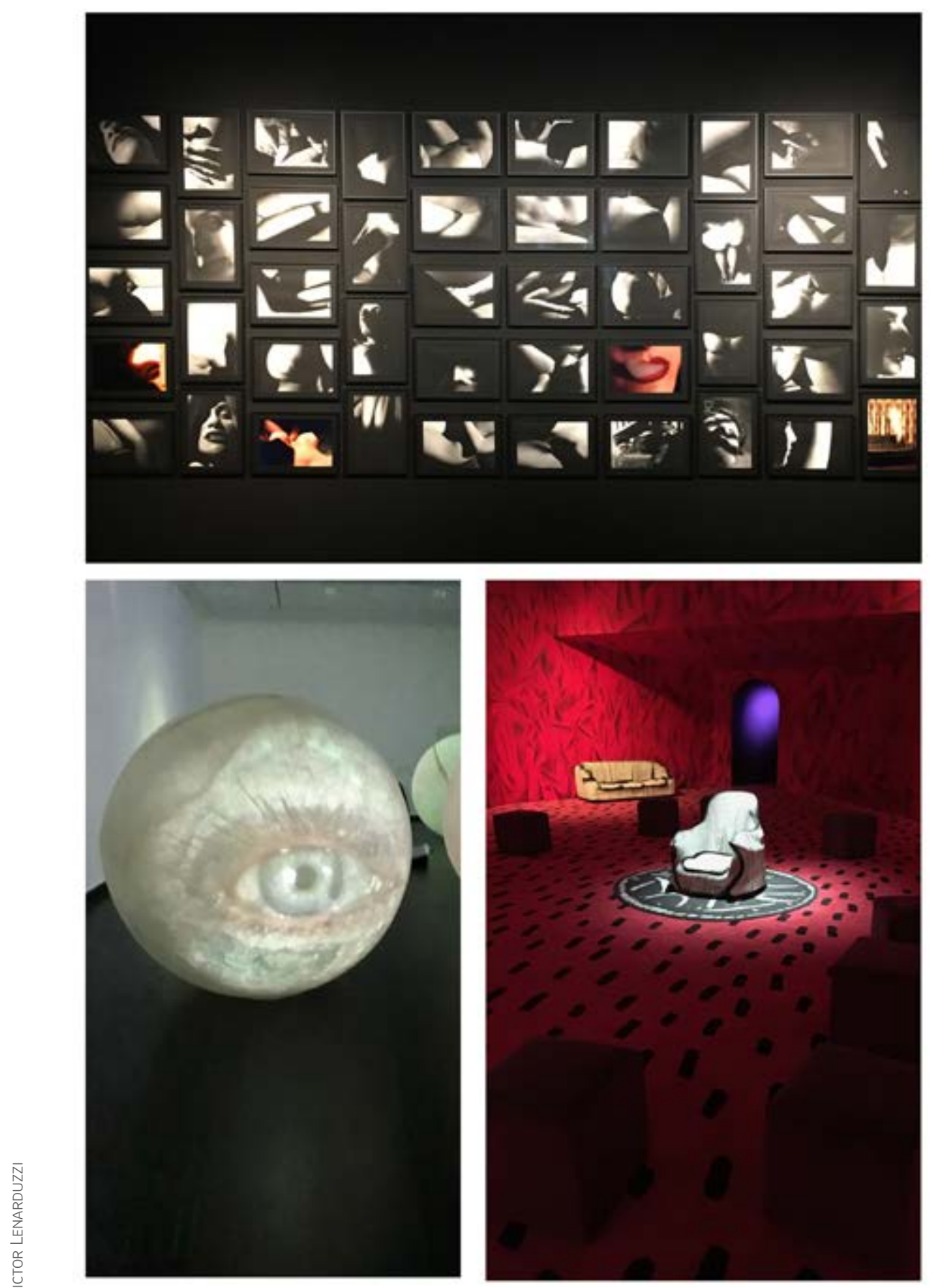

Figura 2. Imágenes de Les Visitants (2017-2018), curaduría de Guillermo Kuitca, Centro Cultural Kirchner, Buenos Aires (foto del autor) 
La pregnancia del curador (no solo en el arte sino en otros ámbitos culturales), los cambios de la institución museo y la mediatización de la cultura también resultan fundamentales en la forma en la que Groys inspecciona el arte contemporáneo. Los museos dejan un poco de ser espacio de colecciones estabilizadas para dar lugar a su rediseño y su movimiento, por lo que se ven transformados en espacios para proyectos curatoriales temporarios:

\begin{abstract}
No por casualidad Harald Szeemann, quien inició el giro curatorial que ha dado el arte contemporáneo, estaba fascinado con la idea de la Gesamtkunstwerk y en 1984 basó una exhibición en ella: «Hang Zum Gesamtkunstwerk» [La tendencia a la Gesamtkunstwerk]. [...] El proyecto curatorial es una Gesamtkunstwerk porque instrumentaliza todas las obras exhibidas, haciéndolas servir a un propósito común que es formulado por el curador (Groys 2016a, pp. 25-26)
\end{abstract}

Y si el museo era el espacio en el que se legitimaban las narrativas dominantes de la historia del arte, los proyectos curatoriales hacen estallar la historia tradicional. Se trata de proyectos - dice Groys - que transforman al museo en una gran instalación, ${ }^{1}$ en una especie de Gesamtkunstwerk temporaria. La variedad de componentes de una instalación puede incluir obras de arte, textos, objetos de la vida cotidiana, sonidos, pantallas, computadoras, iluminación y el propio espacio arquitectónico en el que se produce. En ese marco, la propuesta de Les Visitants se ofrece como una suerte de obra conjunta integrada por diferentes obras cuyo sentido aparece transformado por el espacio en el que opera y las relaciones en las que quedan inscriptas.

El término instalación fue introducido por Michael Fried en un ensayo de 1967 titulado «Arte y objetualidad». En este tipo de realización los diferentes componentes que la integran pierden su autonomía porque quedan al servicio de la totalidad que las incorpora. Esto incluye, muchas veces, también a los visitantes de la instalación que ya no quedan ubicados en una relación de exterioridad con la obra, sino dentro de ella, por lo cual pareciera que «el museo contemporáneo realiza el sueño modernista de un teatro en el que no hay límites claros entre el escenario y el lugar del público- un sueño que el teatro mismo nunca fue capaz de realizar completamente» (Groys, 2016a, p. 28). El autor retoma, además, las elaboraciones de Carl Schmitt en torno al estado de excepción (Ausnahmezustand) como acontecimiento soberano que funda un orden para proponer que «la instalación artística es también un "espacio de excepción": aísla un espacio específico de la topología del mundo "normal" para revelar sus condiciones y determinaciones internas» (Groys, 2016a, p. 102). El curador sería una suerte de dictador para Groys, que funda una nueva situación que niega la dictadura pasada (y contradice su narrativa). Y así los elementos quedan integrados a diferentes relatos y relaciones; la Balada, de Nan Goldin, por ejemplo, queda inscripta en un recorrido en Les Visitants y en otro en Bye Bye American Pie en el Museo de Arte Latinoamericano de Buenos Aires.

1 La otra forma característica del arte contemporáneo — con la que iniciamos- es la performance, un actuación, un acontecimiento al que muchas veces se accede salvo la presencia en el momento en vivo a través de su documentación, no de manera directa. En alguna medida, como se verá, tanto la instalación como la performance pueden funcionar como modelos para pensar diferentes aspectos de la cultura mediática actual. 
¿Qué sucede con las fotos, los videos, los textos que se incorporan al espacio totalizador de la instalación? Podría pensarse que adquieren una nueva condición aurática. Walter Benjamin había señalado el advenimiento de una nueva era para el arte cuando planteó las claves en su conocido ensayo Das Kunstwerk im Zeitalter seiner technischen Reproduzierbarkeit [La obra de arte en la época de su reproductibilidad técnica] [1936] (2010), en el que no solo se refería a nuevas condiciones para la obra de arte reproducida (atrofia del aura), sino, también, a una transformación de la percepción sensorial (Sinneswahrnehmung). Sin embargo, en las condiciones de la mediatización actual y en las formas del arte contemporáneo esta lógica según la cual se reconoce un aura de la obra que tiene un contexto fijo (la tradición) mientras que la copia, dislocada (masivamente distribuida), no permite ese reconocimiento para Groys debería ser pensada nuevamente. Las operaciones de recontextualización pueden proporcionarle un aquí y ahora a la copia, lo que daría lugar a una suerte de retorno del aura en tanto la copia queda inscripta en un contexto específico al que hay que movilizarse para poder acceder a ella (la copia se vuelve original).

Las operaciones de cut \& paste de la cultura digital potencian un rasgo interesante de la creatividad que tiene que ver con la oportunidad que abre a la descontextualización y la recontextualización de las imágenes, los sonidos y los textos; en cierto modo, estas operaciones se pueden pensar en términos de postproducción (Bourriaud, 2007). En Sobre lo nuevo (2005) Groys afirmaba - a propósito del famoso urinario de Duchampque «la falta de originalidad se concibe como un signo especial de originalidad» (p. 139). La copia, situada en un nuevo contexto específico, gana nuevas formas de aura: eso es lo que logra la instalación a la que Groys caracteriza como el «reverso de la reproducción». Como señala el autor en Art Power (2008b) se da aquí una estrategia de transformación de lo repetitivo en algo único.

Hay aquí una cuestión más: Groys vincula aspectos de la vida contemporánea con el linaje del arte conceptual y, así, también se aproxima al contexto más amplio de la cultura mediática actual. Robert Morgan (2003) plantea que el arte conceptual resultaba conflictivo para filósofos, críticos e historiadores del arte que reflexionaban sobre la modernidad, por su énfasis en la idea por sobre el objeto. Groys nos aporta, además, la siguiente cuestión: una clave para leer el arte conceptual es comprender que, como práctica artística, quiso ser significativo y comunicativo. Habitualmente, la función comunicativa del arte quedó subordinada a la función estética. El arte conceptual contribuyó a correr el eje de atención desde el objeto individual hacia el modo en que ese objeto entra en relación con el espacio y el tiempo, de ahí la relevancia de la instalación como género preponderante del arte en los últimos tiempos. A partir de aquí el autor avanza en la siguiente consideración: "La gramática visual de un sitio web no es muy diferente de la gramática del espacio de una instalación. A través de Internet, el arte conceptual se ha vuelto una práctica cultural masiva» (Groys, 2016a, p. 146). Lo que estaría en juego en esta formulación es decidir si es legítimo aceptar que estas prácticas masivamente difundidas en la cultura mediática pueden ser señaladas como prácticas artísticas. ¿Lo son? Quizá se pueda inscribir y discutir esta cuestión en el proceso de estetización de la vida en la Modernidad, que vuelve a poner la idea de una obra total que abarca al conjunto social. 


\section{Estetización de la vida y cultura mediática}

Quiero introducir otra dimensión a partir de la obra Real Nazis de Piotr Uklanski, que pude ver en Documenta 14 en Kassel (2017) [Figura 3]. Se trata de un gran mural rectangular con unos 200 retratos de referentes nazis (desde Adolf Eichmann y Leni Riefensthal, hasta un Hitler marcado, ubicado en el centro) mezclados con fotografías de actores que los encarnaron en la ficción. Una mixtura que remite al horror, pero también a la seducción masiva del cine que les puso otros rostros a esos nombres. Imágenes que nos llevan a interrogarnos: ¿cuántas imágenes de nazis reales construyen nuestra visión del nazismo? ¿Cuánto aportó la cultura de masas a la representación que tenemos de los nazis? ¿Y si ese imaginario fuera solo ficcional? ¿Vale esta pregunta para mucho de lo que hoy es para nosotros una imagen de algo o alguien? La obra es perturbadora e inquietante. Y no solo interroga la relación entre imagen histórica y cinematográfica, sino, también, el espacio más amplio de la relación entre estética y sociedad en el marco de la mediatización de la cultura.

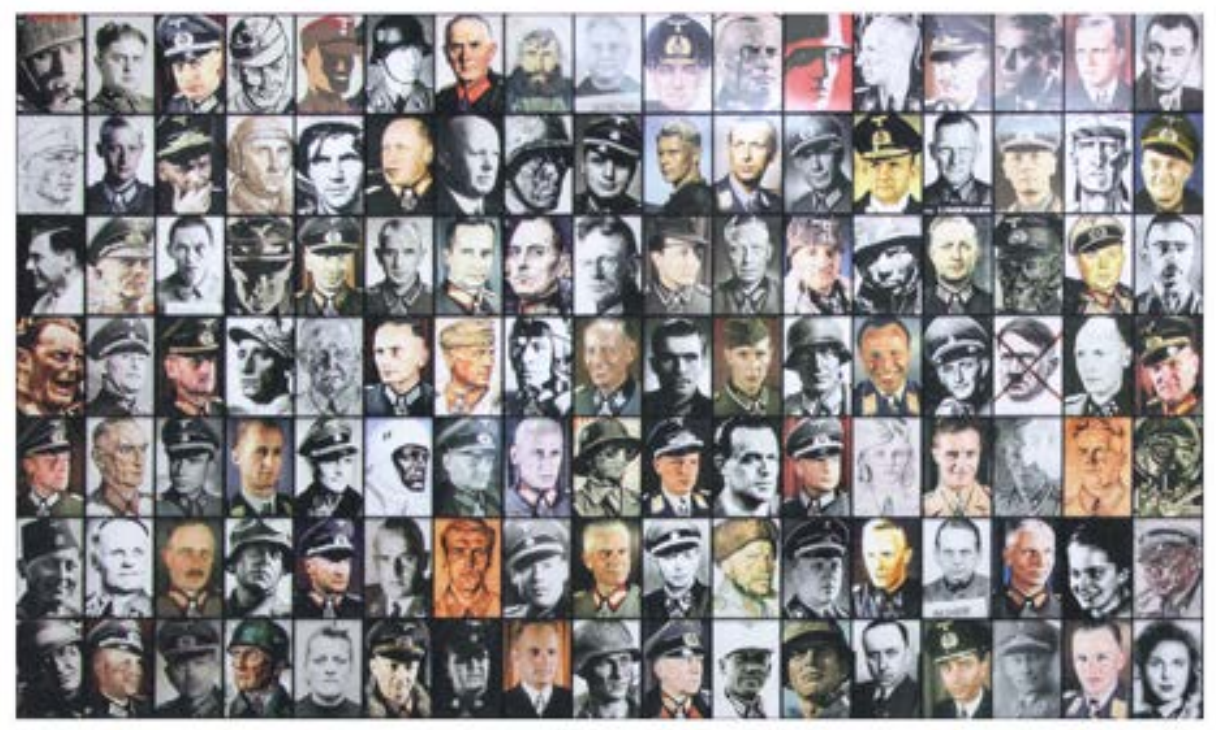

Figura 3. Real Nazis (fragmento) (2017), de Piotr Uklanski. 14 Documenta, Kassel, Alemania (foto del autor)

Esto se puede enfocar desde el epílogo del ensayo sobre la reproductibilidad [1936] (2010) donde Benjamin llamaba la atención acerca del "esteticismo de la vida política» (Ästhetisierung) en el que desembocaba el fascismo, para lo cual cita largamente un manifiesto de Marinetti en el que se repite varias veces que la guerra es bella. Lugar clave y ya clásico para plantear el problema de la estetización de la existencia, pero también problemático al plantear la politización del arte como respuesta certera. Groys considera que no siempre la politización de arte es un antídoto contra la estetización de la política, 
ya que esta última se combina bastante fácilmente con la politización para volverse parte de sus condiciones. Nuevamente resulta representativa la experiencia soviética: «En la Unión Soviética, la estetización de la política se convirtió luego en la politización de lo estético, en el uso de la estética para objetivos políticos — para el diseño político» (Groys, 2016a, p. 67). Por lo cual «el hombre soviético no vivió en esos años dentro de la realidad, sino dentro del arte» (Groys, 2008a, p. 13).

Ahora bien, desde el inicio del siglo XXI se advierte la llegada de otra nueva era, ya no de consumo estético masivo (la anunciada por Benjamin), sino de "producción artística masiva» (Groys, 2014, p. 119). Es indudable que Twitter, Facebook, Instagram, YouTube, Tumblr y otras formas de comunicación ofrecen a la población mundial la posibilidad de presentar fotos, videos y escritos que - en algún punto- no tienen tantas diferencias con una obra de arte postconceptual. En muchos casos, se puede decir que es difícil distinguir algunas prácticas cotidianas del registro documental que los artistas hacen de instalaciones y performances habituales en el arte contemporáneo. De hecho, hay exposiciones de arte que se publicitan a sí mismas como muy instagrameables; a su vez, la vida cotidiana se muestra como una serie de performances y los entornos que la gente habita se exhiben y recorren como instalaciones que se documentan como relevantes ( $y$ tal vez como si fueran arte).La pulsión documentadora de la sociedad actual promete saturar de fuentes no tradicionales a los historiadores del futuro.

¿Qué quiere decir todo esto? Groys (2014) nos dice que «esto significa que el arte contemporáneo se ha vuelto una práctica de la cultura de masas» (p. 97). Aquí vemos por qué reactualiza la categoría wagneriana para interpretar la situación del arte hoy. Por una parte, es casi un lugar común caracterizar la producción artística y cultural contemporánea como participativa y colaborativa. En segundo lugar, suele insistirse en la idea de autoría colectiva (en la que si bien algún individuo puede ser incitador) no podría realizarse sin la intervención conjunta. Finalmente, en esa colaboración resulta indispensable que los artistas interpelen al público y que el público se involucre en la escena artística de la que forma parte (Groys, 2016b).

Son muchos los autores que se han hecho eco de la noción de estetización de la vida que Groys considera vaga y poco específica, además de problemática.

Eduardo Subirats (1989) planteó que el ideal de la obra de arte total —en parte recogido por la vanguardia - se concretó en la actualidad en el diseño estético de lo real y la cultura de espectáculo. Sin embargo, para Groys es posible distinguir entre estetización del diseño y estetización artística. El diseño busca hacer la realidad más atractiva y funcional para los individuos. El arte convierte aquello que estetiza en algo disfuncional, inútil ${ }^{2} y$, por lo tanto, el arte contemporáneo al inscribir la contemporaneidad en el museo anuncia que «no cree en la estabilidad de las condiciones de existencia del presente» (Groys, 2016a, p. 67).

2 Sobre esta caracterización sostiene Groys (2016a): «La Revolución Francesa convirtió los diseños del Antiguo Régimen en lo que hoy llamamos arte, es decir, en objetos no para usar, sino para la pura contemplación. Este acto violento y revolucionario de estetización del Antiguo Régimen creó el arte tal como lo conocemos hoy en día. Antes de la Revolución Francesa no había arte, solo diseño. Después de la Revolución Francesa, el arte emergió como la muerte del diseño» (p. 60) 
Esta cuestión resulta muy atractiva para pensar las relaciones entre arte y cultura mediática. La sociedad actual ha sido muchas veces definida por la espectacularización y la obra de Guy Debord [1967] (2008) fue clave para fundar ese concepto. Allí señaló que "toda la vida de las sociedades donde rigen las condiciones modernas de producción se manifiesta como una inmensa acumulación de espectáculos. Todo lo que antes se vivía directamente se aleja ahora en una representación» (s.p.). De esta manera se constituía una especie de "pseudomundo aparte, objeto de mera contemplación». Para Groys la idea de estetización sugiere esto mismo, una actitud pasiva y contemplativa hacia la sociedad del espectáculo.

A esta altura de las circunstancias es bastante obvio que hay mucha más gente que produce imágenes - sean fotografías o videos, regidas por el ideal de autopresentación ante la mirada del otro- que público dispuesto a contemplarlas. Es importante pensar esto sobre el fondo de ideas de Debord: estaríamos ante una sociedad del espectáculo que se ha quedado sin espectadores dado que todos se han puesto a producir imágenes o en una especie de espectáculo total. ¿Sería esto, entonces, la realización de una Gesamtkunstwerk en la que está implicada la población global?

Ahora bien, Groys señala la relación entre espectáculo y contemplación y nos advierte que en la sociedad actual, la vita contemplativa está sumamente desacreditada, porque lo que hoy se valora es la vita activa. La pregunta, entonces, es quiénes están actualmente en la esa actitud contemplativa. Desde ya, no se puede decir esto de los artistas, pero ya tampoco puede decirse de las masas "porque ellas están también involucradas - consciente o inconscientemente- en prácticas autopoéticas y no tienen tiempo para la pura contemplación» (Groys, 2016, p. 149). Esta circunstancia lleva a Groys a plantear, en la introducción de Volverse público (2014), que quizá sea más adecuado pensar la época contemporánea en términos de poética antes que de estética.

Para formular una caracterización de las prácticas de la comunicación en la cultura mediática actual resulta importante hacer una diferenciación: si el arte modernista y la cultura de masas operaron como conceptos complementarios y el primero definió a la segunda en sentido negativo, cuando nos referimos al arte contemporáneo este puede pensarse en relación con el espacio más amplio de la cultura mediática (o cibercultura o cultura digitalizada, como se prefiera), pero en relaciones nuevas, no fundadas en dicotomías excluyentes. En lugar de reivindicarse como lo auténtico frente a lo falso, diversas formas del arte apuntan más bien a moverse en los bordes, a indagar y a poner en cuestión la experiencia de la contemporaneidad (la obra de Uklanski sería un buen ejemplo). La cultura mediática es la forma hegemónica de la sociedad actual y el arte no está fuera de ella. Sin embargo, algunas formas del arte contemporáneo, al poner el presente bajo sospecha, nos permiten cancelar «la ilusión de que en el reino de los medios digitales todo lo importante sucede en la pantalla» (Groys, 2016b, p. 253). Y además, iluminan posibles aperturas de la cultura mediática a la crítica. Los diferentes usos que Groys hace de la Gesamtkunstwerk permiten indagar sobre estas realidades. 


\section{Referencias}

Benjamin, W. [1936] (2010). Das Kunstwerk im Zeitalter seiner technischen Reproduzierbarkeit. Berlin, Alemania: Surkamp.

Bourriaud, N. (2007). Postproducción. Buenos Aires, Argentina: Adriana Hidalgo.

Debord, G. (2008). La sociedad del espectáculo. Buenos Aires, Argentina: La marca.

Giunta, A. (2014). ¿Cuándo empieza el arte contemporáneo? Buenos Aires, Argentina: Fundación ArteBA.

Groys, B. (2005). Sobre lo nuevo. Ensayo de una economía cultural. Valencia, España: Pre-textos. Groys, B. (2008a). Obra de arte total Stalin. Valencia, España: Pre-textos.

Groys, B. (2008b). Art power. Cambridge, Estados Unidos: MIT Press.

Groys, B. (2014). Volverse público. Las transformaciones del arte en el ágora contemporánea. Buenos Aires, Argentina: Caja Negra.

Groys, B. (2016a). Arte en flujo. Ensayos sobre la evanescencia del presente. Buenos Aires, Argentina: Caja Negra.

Groys, B. (2016b). Introducción a la antifilosofía. Buenos Aires, Argentina: Eterna Cadencia. Huyssen, A. (2001). En busca del futuro perdido. Cultura y memoria en tiempos de globalización. Buenos Aires, Argentina: Fondo de Cultura Económica.

Imhof, A. (2017). Faust [Performance]. Recuperado de https://www.youtube.com/ watch?v=ZNQt7ZILUuM

Jimenez, M. (2010). La querella del arte contemporáneo. Buenos Aires, Argentina: Amorrortu.

Kuitca, G. (Curador). (2017-2018). Les Visitants [Exposición]. Recuperado de http://www.cck. gob.ar/eventos/les-visitants-guillermo-kuitca-y-la-coleccion-de-la-fondation-cartier_2310

Morgan, R. (2003). Del arte a la idea. Ensayos sobre arte conceptual. Madrid, España: Akal.

Smith, T. (2012). ¿Qué es el arte contemporáneo? Buenos Aires, Argentina: Siglo Veintiuno.

Subirats, E. (1989). El final de las vanguardias. Barcelona, España: Anthropos.

Uklanski, P. (2017). Real Nazis [203 impresiones cromogénicas y placa de texto]. Recuperado de https://www.documenta14.de/en/artists/13594/piotr-uklanski

Wagner, R. [1850] (2011). La obra de arte del futuro. En El arte del futuro. Buenos Aires, Argentina: Prometeo. 